\title{
Preliminary Study on Classroom Teaching Reform of Pharmaceutical Botany
}

\author{
Sun Kunlai*; Chen Yin; Qu Youle; Wang Yuqian \\ School of Food and Pharmacy \\ Zhejiang Ocean University \\ Zhoushan 316022, China \\ sunqinlai@126.com
}

\begin{abstract}
This paper attempts to adopt new teaching model of Pharmaceutical Botany course to raise students' interest and enhance their comprehensive practice, innovation and application skills. Through the change of teaching concept, the student-centered core idea is established. By combining theory and practice, displaying students' individual study achievement and sharing resource, their learning efficiency can be comprehensively improved. The attempt of new teaching model has raised students' le arning enthusiasm and subjective initiative, at the same time strengthe ned the ir ability and aware ness of selflearning, and improved the learning interest and efficiency of this course.
\end{abstract}

Keywords-Pharmaceutical Botany; classroom teaching reform; improve efficiency; self-learning

\section{INTRODUCTION}

Pharmaceutical Botany is a discipline that uses botanical knowledge and methods to study plants with healthcare effects, including its morphological structure, physiological functions, classification and identification, resource development, and rational utilization, etc. [1]. It investigates medicinal plant resources and sorts out species of Chinese herbal medicines by studying the morphological description of medicinal plants, as well as classification and identification, thus ensures accurate and effective drug use. As a compulsory basic course for pharmacy and Chinese pharmacy, and the main course of the School of Traditional Chinese Medicine, it plays a connective role among majors of pharmacy and Chinese pharmacy[2], and is closely related follow-up courses like Pharmacology, Traditional Chinese Medicine Identification, Traditional Chinese Medicine Resources, Natural Medicinal Chemistry, Medicinal Plant Cultivation, Medicinal Plant Biotechnology, Traditional Chinese Medicine, Traditional Chinese Medicine Pharmacy, and Traditional Chinese Medicine Processing. [3]

In terms of textbook requirement, the main task of studying Pharmaceutical Botany is to clarify matters from bottom and open source and reduce expenditure. To be general, it is to understand plants and accurately identify plant species, so as to avoid the case where inability to do this lead to waste of resources, even poisoning and risk of patients' lives. Another requirement is to find and expand new medical resources with new technology, according to the relationship among plants, and make medicinal plant resources sustainable.

This work was financially supported by Zhejiang Provincial Natural Science Foundation No. LQ18D060005

\section{Drawbacks of Traditional Teaching Concepts}

The traditional teaching method of this course is basically guided by theoretical teaching, in which teachers explain the basic knowledge to students in class and then link theory with practice. However, this traditional model is not well adapted to a practical discipline like Pharmaceutical Botany[4]. The theory-focused teaching approach makes it difficult to deeply impress students with abstract and boring knowledge like evolution of primary structures and secondary structures, complicated leaf shapes and flower species, common but unfamiliar plant classifications, familiar but not accurately grasped common Chinese medicine effect, let alone stimulate their interest and enthusiasm to study and explore Pharmaceutical Botany

\section{EXPLORE NEW CLASSROOM MODEL}

\section{A. Attempt of Teaching in Student-oriented New Classroom Model}

In the teaching activities, I set a student-oriented and student-centered teaching concept. In my course, I require each student consult literature materials after class, and know well of a medicinal plant, including its habits, characteristics, efficacy, identification of authenticity, etc., and then present and explain it to the whole class with PowerPoint. Meanwhile, each student is required to study and introduce the relevant knowledge in the textbook that is involved in the presentation. Currently, the outcome is satisfactory, and the students show great enthusiasm to prepare their materials. In the beginning of the presentation, their performances are lack of practice, and not natural and confident enough. But as the course developing, learning from and helping each other to improve, the students are gradually familiar with the medicinal plant they are going to introduce, thus achieved nice results. Compared with traditional education, the students make and show the PowerPoint in step with the teaching process in a short period of time, which can maintain the students' continued enthusiasm for the course. Moreover, through collecting and reading literature materials, communicating with each other, during preparation, the students have had some of profound understanding of a plant, which was further deepened by finally explaining it. At the same time, the students' ability to organize, summarize, express, make PowerPoint and present speech are exercised. In the attempt of a semester, in addition 
to the content taught by the teacher, each student mastered nearly 30 kinds of medicinal plants, which greatly improved the learning interest and efficiency. What's more, because of the cooperation and exchanges between the students, some of them planted some medicinal plants they like in the dormitory, which is more conducive to the continuous study of Pharmaceutical Botany after the end of the course.

\section{B. Teaching Method Combining Theoretical Instruction with Innovative Practice}

In the process of teaching this course, we adopt new teaching models in the classroom instruction instead of traditional teaching methods, making full use of various teaching approaches, such as showing pictures of various leaf and flower patterns, and playing video of the growing process from primary structure to secondary structure, etc. By giving positive guidance, we stimulate the students' desire to grasp the knowledge of medicinal plants. In addition, when introducing some important medicinal plants, we interspersed with some folklore stories and anecdotes as appropriate, linking boring theoretical knowledge with luxurious and vivid real life, thus improve students' learning interest and enhance their impression of pharmaceutical effect of these plants. [5] We also guide students to actively understand the habits of plants, distinguish the various species and complex sources of botanical herbs, and know the differences of drug use history and habits in different places. The new teaching model adopted is of great significance. It not only imparts knowledge, but also activates the classroom atmosphere, allowing students to acquire knowledge in a relaxed and comfortable environment.

In the teaching process, the new and forefront knowledge of the discipline is also introduced appropriately, and a series of processes from basic research to development and application of new drugs are explained, for example, the discovery and application of paclitaxel in taxus chinensis. This approach makes the students clearly realize the research process and practical application of natural medicine foster their macro knowledge system, and lay a good foundation for them to become professionals with solid knowledge. By explaining the current high-end technology to enhance students learning interest, we inspire students to form a systematic logical way of thinking to explore the unknown world, and a innovative methods and paths to solve practical problems.

\section{EXISTING DEFICIENCIES AND IMPROVING DIRECTION}

Though the teaching method is relatively creative and is becoming mature in each respect, in the whole teaching process, there are deficiencies and there are improvements to be made.

\section{A. Deficiencies in Students PowerPoint Production and \\ Presentation}

In the process of learning Pharmaceutical Botany, students consult the literature, summarize the key contents, and make PowerPoint to explain it; this great teaching model was encouraged and praised by the principal and supervisor who visited the class. During self-exploration, students are able to achieve the target teaching requirement in Pharmaceutical Botany for a certain medicinal plant, but in the sense of content and knowledge in the assigned PowerPoint, some students spend a relatively long time to deliver their presentation in class, and the key points according to them are neither adequate nor accurate, their introduction is also not specific than that of the teacher. This lead to waste of time in class, and a reduction in interest among student when the teacher begin to comment on and impart new knowledge.

In addition, students also have some problems in setting a proper font size in slides of the PowerPoint. The student can't be specific about this, then the overall typeface in the slide become too large or too small, making other students unable to see it clearly, or unwilling to look at the slide due to too many words. In addition, students can't play the PowerPoint in a proper speed, some shift too fast, some don't further explain things that shown in the slides and let the classmates read by themselves. Due to the fact that other students have little patience to read a great deal of words, much time and content that could have been explained are lost. Finally, the student rely too much on the PowePoint during presentation, staring at and reading the slides word by word, with little or no special performance, making the effect of delivery unsatisfactory.

\section{B. Existing Problems in the Learning Process of Students}

In one semester of study, the students were confused of learning some part of knowledge. During the learning process, some basic concepts (terms) were not well grasped, which affected the learning of the follow-up content in class. The inability of the students to understand, familiarize with and master the knowledge learned in a timely manner, such as the basic concepts like root, stem, leaf, flower and fruit, etc., results in the failure of effective understanding and grasp of following Taxonomy course( such as the characteristics of each species, microscopic features, etc.). When study the microstructure, students can't learn the meaning and theoretical content in the pictures well, thus find it difficult and confusing when they memorize the key content. The experiment course is arranged after the end of the theory course, which also leads to the lack of timely training in experiment and practice, resulting that insufficient the characteristics of various subjects and micro-structure in Taxonomy is not solidly grasped, or easy to make mistakes.

\section{Improving Plan and Direction in Classroom Teaching Next Semester}

\section{1) Requirements for Students to Make PowerPoint}

When assigning students to start summarizing and making PowerPoint, specific requirements should be given (such as format, font, contrast, etc.), these unified regulations in addition to the content will ensure the improvement of delivery effect.

\section{2) Adopt Both Theory and Practice Teaching}

In the study of Pharmaceutical Botany, experimental class and theoretical class should be carried out simultaneously or alternately, so that at the same time of learning the theoretical course, the students strengthen the grasp of knowledge in the class through the visual image of experimental class, and also learn more about the basic nouns and the microstructure in the experiment. As the saying goes: do once is better than looking 
over a thousand times. Learning is the same, look real things in the lab is better than watch ten thousand pictures online. The Pharmaceutical Botany course will set outdoors learning and add practical sector, arrange proper class hour specially, and lead the students to places with abundant plants around the campus to meet some plants with medicinal value. Combination of theory and practice is also viable. [6] When students go out to play, they will encounter strange plants, for those really strange or intriguing; students can set down its characteristics, and see help to know its relevant habits and pharmaceutical value. This learning approach needs to be upheld in long-term in the course Pharmaceutical Botany.

\section{3) Add Local Special Content into Teaching Practice}

I work in Zhejiang Ocean University in Zhoushan city, this is a magical place with plenty of miraculous plants that I can make use of. In light of local specialty, we can add some medicinal plants with local specialty or marine medicinal plant into the content of Pharmaceutical Botany course.

\section{CONCLUSION}

China has a long history of medicinal plants use; our predecessors left us a bright treasure of knowledge. However, it is far from enough for us today to do a good job in studying Pharmaceutical Botany simply by reading piles of successful books and not putting it into practice. 'Everything must be only done then been understood profoundly, "[7] Although it will be difficult to carry out the classroom teaching reform, I firmly believe that we will find the ideal teaching model through trying again and again. I will continue to interact with students in the course of practice, collect feedback in a timely manner, and identify and improve deficiencies in the curriculum. I will also continue to improve my teaching competence, and enhance the enthusiasm of students. At the same time, it is necessary to focus on the daily accumulation of learning and always keep positive to the surrounding plants. Meanwhile, I will pay attention to the links among other disciplines, the interaction and application of Botany, Pharmacology, Traditional Chinese Medicine, and ultimately form a set of learning methods and even research ideas of my own. I will make unremitting effort to prevent classroom teaching reform from becoming a mere formality or being ruined carelessly.

\section{REFERENCES}

[1] Huang Baokang. Pharmaceutical Botany (7th Edition) [M]. Beijing: People's Medical Publishing House, 2016.03.

[2] Yang Chunshu, Zeng Wanzhang, Liu Wenliang, et al. Pharmaceutical Botany [M]. Shanghai: Shanghai Science and Technology Press, 1997.1.

[3] Sun Kunlai, Chen Yin, Qu Youle, et al. The teaching reform of medicinal botany [J]. Advances in Economics, Business and Management Research, 2017, 49: 67-70.

[4] Ou Lilan, Zhu Xi, Li Ting et al. Exploration of the reform of medicinal botany teaching [J]. Exam Weekly, 2018, 1:10-11.

[5] Wu Shun, Cai Yan. Innovative Education in the Teaching of Molecular Biology Theory [J]. Anhui Agricultural Science Bulletin, 2018, 24 (05): 111-118.

[6] Dong Xiangkai, Shao Shiguang, Wang Ling. Exploration of the construction of medicinal botany extracurricular practice teaching platform [J]. Career, 2017, 32: 80-81.

[7] Lin Wei, Chen Caiyun, Wang Yinglin, Yu Jingping. Exploration on the teaching reform of medicinal botany in undergraduate specialty of traditional Chinese medicine[J]. Modern Distance Education of Chinese Medicine, 2017, 19:31-33. 